\title{
Correlation analysis of olympic-style weightlifting exercises and vertical jumps
}

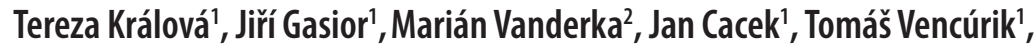 \\ Dominik Bokůvka' ${ }^{1}$ Tereza Hammerová1
}

\begin{abstract}
Masaryk University Faculty of sports studies Brno Czech Republic',
Comenius University in Bratislava Faculty of Physical Education and Sports Bratislava Slovak Republic ${ }^{2}$
\end{abstract}

\begin{abstract}
PURPOSE Many types of vertical jumps (VJ) are commonly used to assess the development of the level of explosive strength of lower limbs achieved after a training period. This study is focused on comparing various parameters of different types of $V J$ with 1 RM in Olympic-style weightlifting, squat and deadlift with an Olympic bar.

METHODS Twelve elite weightlifters ( men $=8$; women $=4$; age $26 \pm 4$ years, height $=173 \pm 8 \mathrm{~cm}$; weight $93 \pm 23 \mathrm{~kg}$; weight category from $64 \mathrm{~kg}$ to $+109 \mathrm{~kg}$ ) were tested for 1 RM in the following exercises: snatch, clean and jerk, deadlift, squat and variations of $\mathrm{VJ}$ on dynamometric plates (Kistler Force Plate). The variations of VJ were: squat jump with the arm swing (SJA) and non-arm swing (SJ), countermovement jump with the arm swing (CMJA) and non-arm swing (CMJ). The parameters compared for each type of $V J$ were: jump height $(\mathrm{m})$, relative force (\% of body weight), relative power (W/kg of body weight) and average power (W). For statistical analysis, the parametric Pearsons correlation coefficient with $a=0.05$ was used.

RESULTS The results show a significant correlation between 1 RM in exercises with an Olympic bar (snatch, clean and jerk, back squat and deadlift) and the CMJ, CMJA, SJ and SJA only in the average power output $(W)$ parameter $(p<0.05)$. The significant correlation coefficients in the average power output (W) were for the CMJA and the snatch $r=0.96 r^{2}=0.92$, clean and jerk $r=0.96 r^{2}=0.92$, back squat $r=0.97 r^{2}=0.94$ and deadlift $r=0.93 r^{2}=0.86 ; C M J$ with hands on the hips and the snatch $r=0.93$ $r^{2}=0.86$, clean and jerk $r=0.93 r^{2}=0.86$, back squat $r=0.95 r^{2}=0.90$ and deadlift $r=0.94 r^{2}=0.88 ;$ for the SJA and the snatch $r=0.8 r^{2}=0.64$, clean and jerk $r=0.81 r^{2}=0.65$, back squat $r=0.82 r^{2}=0.67$ and deadlift $r=0.78 r^{2}=0.60$; for the SJ with hands on the hips and the snatch $r=0.76 r^{2}=0.57$, clean and jerk $r=0.75 r^{2}=0.56$, back squat $r=0.77 r^{2}=0.59$ and deadlift $r=0.71 r^{2}=0.50$. Significant correlation coefficients were not found for 1 RM in the snatch, clean and jerk, back squat and deadlift and the CMJ or SJ with and without arm swing in any of the following parameters: jump height $(\mathrm{m})$, relative force (\% of body weight), relative power output (W/kg of body weight).

CONCLUSION The main finding is that the jump height $(m)$ of the CMJ or SJ with or without arm swing did not correlate significantly with 1 RM in the snatch, clean and jerk, back squat and deadlift. Therefore, jump height measurement can be used as a motivation tool but not to predict maximum strength in Olympic bar exercises, or vice versa. We recommend using the average power output (W) parameter in the CMJ with using arms as a predictor of current performance level in exercises with an Olympic bar for men and women.
\end{abstract}

Key words: snatch, clean and jerk, squat, deadlift, countermovement jump, squat jump 


\section{INTRODUCTION}

Weightlifting is one of the few sports to have been featured at the 1896 Athens Games (Olympic. org, 2019), but nowadays it is fighting for its place. Taking into account that weightlifting in its various forms creates the potential of strength for all sports, we have to start asking how to train weightlifting efficiently and how it is reflected in other sports. One of these options is to refine testing methods, which provide metrics of current performance and motivate not only adults but also young athletes to stay dedicated to training. All this while respecting the principles of drug-free sport.

A very successful weightlifting coach named Bob Takano claims that jumping exercises (from a quarter and full squat) are the most helpful modalities for weightlifters in the general physical preparation phase for generating explosive force from the legs and hips (Takano, 2012). Explosive force is reflected primarily in the improvement of the power snatch and clean and jerk exercises in a classic weightlifting training. On the other hand, performing squats (loaded with 56\% of $1 \mathrm{RM}$ ) or power cleans (loaded with $80 \%$ of $1 \mathrm{RM}$ ) could supplement jumping in the process of developing power, if we assume the theory that if an athlete jumps or runs with their own bodyweight it is considered power training (McGuigan, 2017). Many types of jumping exercises can be used to examine the level of explosive force development during the preparation training phase and the competition training phase.

Many researchers are focused on a possible positive effect of weightlifting and utilizing heavy squats on the performance in dynamic exercises including the vertical jump and vice versa. Positive results were found both in terms of a short-term (4-8 weeks) effect (Otto III, Coburn, Brown, \& Spiering, 2012; Tricoli, Lamas, Carnevale, \& Ugrinowitsch, 2005;) and an acute effect pre-workout (or post-activation potentiation effect) (Duthie, Young, \& Aitken, 2002; Borba, Ferreira-Júnior, Santos, Carmo, \& Coelho, 2017 ), although the success of the PAP effect depends on many factors (Robbins, 2005). To provide the best results in the explosive strength and vertical jump performance in general, it is commonly recommended to use a combination of traditional Olympic-style weightlifting exercises and plyometric drills (Fatouros, Jamurtas, Leontsini, Taxildaris, Aggelousis, Kostopoulos, \& Buckenmeyer, 2000). Not all sports require training in only jumping high, but also in jumping as quickly as possible. For example, track and field athletes who want to jump high or jump far use their arms to reach the maximum jump height. Harman, Rosenstein, Frykman, \& Rosenstein (1990) say that for these athletes it is more effective to train the countermovement jump with an arm swing in contrast to those who want to jump quickly for blocking in volleyball with one's arms raised where it is better to train the countermovement jump without an arm swing.

Training halls in which weightlifting and sports training are mostly performed are not equipped with modern testing technology. For this reason, many coaches use the vertical jump height in centimeters as an indicator of the explosive force of the legs and hips. It is routinely tested in the vertical countermovement jump with an arm swing movement when jumping onto a stack of weight plates, which is made progressively higher. Coaches and athletes often place too much importance on the result of the vertical jump test, but we don't have enough research to link the result with actual weightlifting performance or vice versa. Only one study has examined the relationship between vertical jumps (CMJ and $\mathrm{SJ}$ ) and weightlifting performance. The results of this study indicate that the Power Peak derived from the vertical jump (CMJ or SJ) can be a valuable tool in assessing weightlifting performance (Carlock, Smith, Hartman, Morris, Ciroslan, Pierce, ... \& Stone, 2004). Unfortunately, this study compared weightlifting performance only to vertical jumps with hands on the hips. However, weightlifting involves complex movements, and it cannot be performed well without combining the explosive strength of the lower and upper limbs. We believe that it is necessary to include variants of vertical jumps with an arm swing in the comparison as well. 
The purpose of our research was to examine the correlation between variations of VJ (squat jump with (SJA) and without (SJ) an arm swing; countermovement jumps with (CMJA) and without (CMJ) the arm swing), and the snatch, clean and jerk, back squat and deadlift.

\section{METHODS}

Twelve elite weightlifters $($ men $=8$; women $=4$; age $26 \pm 4$ years, height $=173 \pm 8 \mathrm{~cm}$; weight $=$ $93 \pm 23 \mathrm{~kg}$ (mean $\pm \mathrm{SD}$ ); weight categories from $64 \mathrm{~kg}$ to $+109 \mathrm{~kg}$ ) from the Czech Republic took part in a research that compared the results of exercises performed with the Olympic bar and different types of vertical jumps by means of a correlation analysis. Each of the weightlifters had competed at more than one international competition (World Championship or European Championship) in Olympic-style weightlifting and had been doing a focused weightlifting training for a minimum of six years.

All weightlifters were tested for their $1 \mathrm{RM}$ in the following exercises: snatch, clean and jerk, deadlift, squat and variations of VJ on dynamometric plates (Kistler Force Plate) in the course of ten days. The results of the snatch and clean and jerk were taken from weightlifting competitions. For the correlation, the best result in the snatch and clean and jerk was considered. To minimize false testing of $1 \mathrm{RM}$ in competition (without the possibility of multiple attempts), we also regarded the results that were not recognized by referees as "good attempts" due to movement in the elbows, but the weightlifter held the barbell over their head as $1 \mathrm{RM}$. The $1 \mathrm{RM}$ testing was spread over several days of the week with the testing of vertical jumps being done a minimum of 48 hours after the $1 \mathrm{RM}$ testing or before the $1 \mathrm{RM}$ testing. The $1 \mathrm{RM}$ testing was done in the traditional manner of $1 \mathrm{RM}$ testing for weightlifters. After a basic warm-up and dynamic stretching, they warmed-up with the Olympic bar up to $60 \%$ of their 1 RM. Then they tried to reach their maximum in 8-12 series gradually with one repetition on each weight. The rest between the repetitions was usually 2-3 minutes between the attempts with the weight at $60-90 \%$ of their $1 \mathrm{RM}$, and usually 3-6 minutes between the attempts with the weight over $90 \%$ of their $1 \mathrm{RM}$ as recommended by Bomba and Buzzichelli (2015). For the 1 RM testing of the back squat, the version used was the high bar position on the shoulders with the deepest range of motion possible but always under the parallel position of the tights, close to $50^{\circ}$ at the knee joint.

The subjects jumped from the force platform with maximal effort in four different ways: squat jump with an arm swing (SJA) and squat jump without an arm swing (SJ), countermovement jump with an arm swing (CMJA) and countermovement jump without an arm swing (CMJ). The starting position for all countermovement jumps was an upright position with the hands on the hips or with the arms behind the back prepared for the arm swing. The starting position for the squat jumps was with the knee joints at $90^{\circ}$ with the hands on the hips or with the arms behind the back prepared for the arm swing. The lowest position during the jumps was with the knee joints at $90^{\circ}$. The subjects performed three trials of each jump type for a total of 12 jumps and rested between the jumps, usually for 3-min. Each subject was carefully instructed in the proper technique of the different types of jumps. It took two to three practice jumps at submaximal effort before measuring to ensure that the jump-type was being performed correctly. No attempt was made to directly measure or control the degree of bending in the knee. The variations of VJ were: squat jump with an arm swing (SJA) and without an arm swing (SJ), countermovement jump with an arm swing (CMJA) and without an arm swing (CMJ). The parameters compared for each type of VJ were: jump height $(\mathrm{m})$, relative force (\% of body weight), relative power $(\mathrm{W} / \mathrm{kg}$ of body weight) and average power (W).

For statistical analysis, after the expected normality of the data distribution according to the Shapiro-Wilk test was met, the data were analyzed with the parametric Pearsons correlation coefficient with $\alpha=0.05$. The parameters of the Kistler Plates used: model dual Portable Force 
Plate 600x500x50 mm type 9260AA6. Software MARS (Measurement, Analysis and Reporting Software).

All participants gave their written consent to participate in the research. The consents were consistent with the ethical standards in research at MU and approved.

\section{RESULTS}

The reported performance of all the weightlifters (women and men together) in the countermovement jumps (CMJ) with and without (hands on hips) an arm swing is shown in Table 1. Only the correlation coefficient for the average power output (W) parameter was statistically significant for both variants of the CMJ with all the 1RM test parameters in the exercises with an Olympic-bar.

Tab. 1: Pearsons correlation coefficients for countermovements jumps for both men and women together $(n=12)$

\begin{tabular}{|l|c|c|c|c|c|c|c|c|}
\hline & \multicolumn{4}{|c|}{ CMJ with arm swing (CMJA) } & \multicolumn{3}{c|}{ CMJ with hands on hips (CMJ) } \\
\cline { 2 - 8 } & $\begin{array}{c}\text { Jump } \\
\text { Height } \\
(\mathrm{m})\end{array}$ & $\begin{array}{c}\text { Relative } \\
\text { Force } \\
(\% \mathrm{BW})\end{array}$ & $\begin{array}{c}\text { Relative } \\
\text { Power } \\
(\mathrm{W} / \mathrm{kg})\end{array}$ & $\begin{array}{c}\text { Average } \\
\text { Power } \\
(\mathrm{W})\end{array}$ & $\begin{array}{c}\text { Jump } \\
\text { Height } \\
(\mathrm{m})\end{array}$ & $\begin{array}{c}\text { Relative } \\
\text { Force } \\
(\% \mathrm{BW})\end{array}$ & $\begin{array}{c}\text { Relative } \\
\text { Power } \\
(\mathrm{W} / \mathrm{kg})\end{array}$ & $\begin{array}{c}\text { Average } \\
\text { Power } \\
(\mathrm{W})\end{array}$ \\
\hline $\begin{array}{l}\text { Snatch } \\
(\mathrm{kg})\end{array}$ & 0.563875 & 0.333178 & 0.448767 & $\mathbf{0 . 9 6 2 0 4 3 ^ { * }}$ & 0.399235 & 0.299596 & 0.417465 & $\mathbf{0 . 9 3 9 5 9 8}^{*}$ \\
\hline $\begin{array}{l}\text { Clean and } \\
\text { jerk (kg) }\end{array}$ & 0.540905 & 0.306653 & 0.429659 & $\mathbf{0 . 9 6 3 3 4 7 ^ { * }}$ & 0.363685 & 0.266328 & 0.385365 & $\mathbf{0 . 9 3 4 0 6 4}^{*}$ \\
\hline $\begin{array}{l}\text { Back squat } \\
\text { (kg) }\end{array}$ & 0.518168 & 0.326583 & 0.382336 & $\mathbf{0 . 9 7 3 7 1 4 ^ { * }}$ & 0.339815 & 0.322730 & 0.380403 & $\mathbf{0 . 9 5 6 4 3 0 ^ { * }}$ \\
\hline $\begin{array}{l}\text { Deadlift } \\
\text { (kg) }\end{array}$ & 0.400937 & 0.180948 & 0.233943 & $\mathbf{0 . 9 3 5 1 9 0 ^ { * }}$ & 0.218970 & 0.152343 & 0.224558 & $0.942512^{*}$ \\
\hline
\end{tabular}

*statistically significant $(\mathrm{p}<0.05)$

The reported performance of all the weightlifters (women and men together) in the squat jumps (SJ) with and without (hands on hips) an arm swing is shown in Table 2. Only the correlation coefficient for the average power output (W) parameter was statistically significant for both variants of the SJ with all the 1RM test parameters in the exercises with an Olympic-bar.

Tab. 2: Pearsons correlation coefficients for squat jumps for both men and women together $(n=12)$

\begin{tabular}{|l|c|c|c|c|c|c|c|c|}
\hline & \multicolumn{4}{|c|}{ SJ with arm swing (SJA) } & \multicolumn{3}{c|}{ SJ with the hands on hips (SJ) } \\
\cline { 2 - 9 } & $\begin{array}{c}\text { Jump } \\
\text { Height } \\
(\mathrm{m})\end{array}$ & $\begin{array}{c}\text { Relative } \\
\text { Force } \\
(\% \mathrm{BW})\end{array}$ & $\begin{array}{c}\text { Relative } \\
\text { Power } \\
(\mathrm{W} / \mathrm{kg})\end{array}$ & $\begin{array}{c}\text { Average } \\
\text { Power } \\
(\mathrm{W})\end{array}$ & $\begin{array}{c}\text { Jump } \\
\text { Height } \\
(\mathrm{m})\end{array}$ & $\begin{array}{c}\text { Relative } \\
\text { Force } \\
(\% \mathrm{BW})\end{array}$ & $\begin{array}{c}\text { Relative } \\
\text { Power } \\
(\mathrm{W} / \mathrm{kg})\end{array}$ & $\begin{array}{c}\text { Average } \\
\text { Power } \\
(\mathrm{W})\end{array}$ \\
\hline $\begin{array}{l}\text { Snatch } \\
(\mathrm{kg})\end{array}$ & 0.567742 & 0.314079 & 0.433825 & $\mathbf{0 . 8 0 2 2 4 6 *}$ & 0.492791 & 0.315427 & 0.282253 & $\mathbf{0 . 7 6 1 1 3 6 *}$ \\
\hline $\begin{array}{l}\text { Clean and } \\
\text { jerk (kg) }\end{array}$ & 0.534589 & 0.316329 & 0.422577 & $\mathbf{0 . 8 1 1 6 5 7 ^ { * }}$ & 0.455916 & 0.285934 & 0.251348 & $\mathbf{0 . 7 5 8 7 1 7 *}^{*}$ \\
\hline $\begin{array}{l}\text { Back squat } \\
\text { (kg) }\end{array}$ & 0.539559 & 0.346272 & 0.438173 & $\mathbf{0 . 8 2 7 7 9 2 *}$ & 0.449647 & 0.323585 & 0.274748 & $\mathbf{0 . 7 7 3 8 4 8 *}^{*}$ \\
\hline $\begin{array}{l}\text { Deadlift } \\
\text { (kg) }\end{array}$ & 0.398124 & 0.283512 & 0.293510 & $\mathbf{0 . 7 8 3 0 6 4 *}$ & 0.284477 & 0.163797 & 0.098859 & $0.719876^{*}$ \\
\hline
\end{tabular}

*statistically significant $(\mathrm{p}<0.05)$ 
As can be seen from Table 1 and Table 2, the correlation coefficients between the 1RM exercises with an Olympic-bar and all types of vertical jumps used have higher statistically significant correlation coefficients in the CMJ and CMJA compared to the SJ and SJA.

The reported performance for men only $(n=8)$ in the countermovement jumps $(C M J)$ with and without (hands on hips) an arm swing is shown in Table 3. All the monitored parameters of the CMJ (without an arm swing) statistically significantly correlated with all the 1RM test parameters in the exercises with an Olympic-bar. Unlike the other monitored parameters, only the average power output parameter correlates significantly positively. The only parameters that have a significant correlation coefficient with the CMJA (with an arm swing) were the production of relative force (negative correlation coefficient) and the production of average power output (positive correlation coefficient).

Tab. 3: Pearsons correlation coefficients for the countermovement jumps for men $(n=8)$

\begin{tabular}{|c|c|c|c|c|c|c|c|c|}
\hline & \multicolumn{4}{|c|}{ CMJ with arm swing (CMJA) } & \multicolumn{4}{|c|}{ CMJ with hands on hips (CMJ) } \\
\hline & $\begin{array}{l}\text { Jump } \\
\text { Height } \\
\text { (m) }\end{array}$ & $\begin{array}{l}\text { Relative } \\
\text { Force } \\
(\% \mathrm{BW})\end{array}$ & $\begin{array}{l}\text { Relative } \\
\text { Power } \\
(\mathrm{W} / \mathrm{kg})\end{array}$ & $\begin{array}{l}\text { Average } \\
\text { Power } \\
\text { (W) }\end{array}$ & $\begin{array}{l}\text { Jump } \\
\text { Height } \\
\text { (m) }\end{array}$ & $\begin{array}{l}\text { Relative } \\
\text { Force } \\
(\% \mathrm{BW})\end{array}$ & $\begin{array}{c}\text { Relative } \\
\text { Power (W/ } \\
\text { kg) }\end{array}$ & $\begin{array}{l}\text { Average } \\
\text { Power } \\
\text { (W) }\end{array}$ \\
\hline $\begin{array}{l}\text { Snatch } \\
(\mathrm{kg})\end{array}$ & -0.573376 & $-0.879680^{*}$ & -0.618348 & $0.828485^{*}$ & $-0.829422^{*}$ & $-0.880782^{*}$ & $-0.736152^{*}$ & $0.820774^{*}$ \\
\hline $\begin{array}{l}\text { Clean and } \\
\text { jerk }(\mathrm{kg})\end{array}$ & -0.565938 & $-0.862002 *$ & -0.579998 & $0.871802^{*}$ & $-0.808542 *$ & $-0.847151^{*}$ & $-0.708443^{*}$ & $0.854790 *$ \\
\hline $\begin{array}{l}\text { Back } \\
\text { squat (kg) }\end{array}$ & -0.646068 & $-0.786960^{*}$ & $-0.736573^{*}$ & $0.900732^{*}$ & $-0.903932 *$ & $-0.714265^{*}$ & $-0.743880^{*}$ & $0.903130^{*}$ \\
\hline $\begin{array}{l}\text { Deadlift } \\
(\mathrm{kg})\end{array}$ & -0.646366 & $-0.846624^{*}$ & $-0.777619^{*}$ & $0.829092^{*}$ & $-0.859801^{*}$ & $-0.791277^{*}$ & $-0.807195^{*}$ & $0.887157^{*}$ \\
\hline
\end{tabular}

*statistically significant $(\mathrm{p}<0.05)$

The reported performance for men only $(n=8)$ in the squat jumps $(\mathrm{SJ})$ with and without (hands on hips) an arm swing is shown in Table 4. No significant correlation coefficients were observed between the SJA and the 1RM in the exercises with an Olympic bar, not even for the average power output parameter (W). Significant correlation coefficients are generally lower in the SJ than in the CMJA and CMJ. Unfortunately, none of the SJA parameters correlated significantly positively with any of the 1RM tests in the exercises with an Olympic-bar.

Tab. 4: Pearsons correlation coefficients for the squat jumps for men $(n=8)$

\begin{tabular}{|l|c|c|c|c|c|c|c|c|}
\hline & \multicolumn{4}{|c|}{ SJ with arm swing (SJA) } & \multicolumn{4}{c|}{ SJ with hands on hips (SJ) } \\
\cline { 2 - 9 } & $\begin{array}{c}\text { Jump } \\
\text { Height } \\
(\mathrm{m})\end{array}$ & $\begin{array}{c}\text { Relative } \\
\text { Force } \\
(\% \mathrm{BW})\end{array}$ & $\begin{array}{c}\text { Relative } \\
\text { Power } \\
(\mathrm{W} / \mathrm{kg})\end{array}$ & $\begin{array}{c}\text { Average } \\
\text { Power } \\
(\mathrm{W})\end{array}$ & $\begin{array}{c}\text { Jump } \\
\text { Height } \\
(\mathrm{m})\end{array}$ & $\begin{array}{c}\text { Relative } \\
\text { Force } \\
(\% \mathrm{BW})\end{array}$ & $\begin{array}{c}\text { Relative } \\
\text { Power }(\mathrm{W} / \\
\mathrm{kg})\end{array}$ & $\begin{array}{c}\text { Average } \\
\text { Power } \\
(\mathrm{W})\end{array}$ \\
\hline $\begin{array}{l}\text { Snatch } \\
\mathrm{kg})\end{array}$ & -0.609987 & -0.681462 & -0.548741 & 0.486529 & -0.594691 & $-0.782088^{*}$ & -0.592836 & 0.485422 \\
\hline $\begin{array}{l}\text { Clean and } \\
\text { jerk (kg) }\end{array}$ & -0.635081 & -0.637116 & -0.504150 & 0.530024 & -0.590824 & $-0.763252 *$ & -0.555892 & 0.532730 \\
\hline $\begin{array}{l}\text { Back } \\
\text { squat (kg) }\end{array}$ & -0.613839 & -0.518869 & -0.452827 & 0.572662 & -0.640316 & -0.663179 & -0.525038 & 0.539215 \\
\hline $\begin{array}{l}\text { Deadlift } \\
\text { (kg) }\end{array}$ & -0.682372 & -0.431406 & -0.558064 & 0.484555 & $-0.743014 *$ & $-0.736194 *$ & -0.671563 & 0.443945 \\
\hline
\end{tabular}

*statistically significant $(\mathrm{p}<0.05)$ 


\section{DISCUSSION}

The limitation of this study is the very small number of participants, but it is caused by the fact that there are no more weightlifters at an elite level in the Czech Republic. In order to conduct further research, we would suggest obtaining more individuals for testing (men and women) from the field of Olympic weightlifting, and other sports to compare their performance with one another, or possibly add another intervention factor. Another limitation is the large body mass weight difference of the weightlifters. Due to the small number of tested persons overall, it was not possible to divided them into individual weight categories and then perform a corelation analysis.

In research like this, it is not common to evaluate the results of men and women together. And the fact that we compared parameters in women and men as one homogeneous group could be considered questionable. This methodological decision stems from the practical issue, that trainers test both men and women together and mostly record only the jump height parameter. Therefore, we decided to consider men and women as a single group to test whether it is possible to take at least one parameter as an indicator of performance across the board. That is why we performed a correlation analysis for men and women together and then one for men only. This subsequent verification of our results showed us that the results of the correlation analysis of the squat jump (SJA and SJ) for men and women together could be distorted by the number of participants, as the SJ and SJA do not correlate significantly with the results of a 1RM in the exercises with an Olympic-bar in the group of men only.

If we compare our results to other studies with a similar focus, we must consider the types of strength exercises with which they correlate each type of vertical jumps. In the study by Nuzzo, McBride, Cormie, \& McCaulley (2008) significant correlations $(p \leq 0.05)$ were found when comparing relative strength ( $1 \mathrm{RM} /$ body mass) in both the squat and power clean to relative CMJ peak power, CMJ peak velocity, and CMJ height. In our study, it was shown that the squat (deep squat) correlated significantly with the CMJ jump height, but negatively. In the research by Carlock et al. (2004) the results showed that a maximum vertical jump performance in the $\mathrm{CMJ}$ or $\mathrm{SJ}$ in the power peak production is strongly associated with the 1RM of the weightlifting exercises (snatch, clean and jerk). And these types of vertical jumps can be a useful tool in achieving the best performance in Olympic weightlifting. However, this research, unlike ours, was performed on vertical jumps without an arm swing (CMJ and SJ) only and the data for the current weightlifting performance were taken from questionnaires given to both men and women. This study was also supported by Everett (2016) claiming that vertical jumps (countermovement and squat jumps) are useful exercises for explosiveness and elasticity during the second pull phase in the snatch and clean. The results of our research have shown that the snatch and clean and jerk in men correlate statistically significantly with the countermovement jump with an arm swing in the relative strength (negative correlation coefficient) and the average power output (positive correlation coefficient).

\section{CONCLUSION}

The main finding is that the jump height $(\mathrm{m})$ of the CMJ or SJ with or without arm swing did not correlate significantly with 1 RM in the snatch, clean and jerk, back squat and deadlift. Therefore, jump height measurement can be used as a motivation tool but not to predict maximum strength in Olympic bar exercises, or vice versa. We recommend using the average power output (W) parameter in the $\mathrm{CMJ}$ with using an arm swing as a predictor of current performance level in exercises with an Olympic bar for men and women. 


\section{ACKNOWLEDGMENTS}

The implementation of the research was approved by the Ethics Committee for Research of Masaryk University in Brno.

Mgr. Tereza Králová: tereza.kralova@fsps.muni.cz

\section{References}

Bompa, T., \& Buzzichelli, C. (2015). Periodization Training for Sports, 3E. Human kinetics.

Borba, D. D. A., Ferreira-Júnior, J. B., Santos, L. A. D., Carmo, M. C. D., \& Coelho, L. G. M. (2017). Effect of post-activation potentiation in Athletics: a systematic review. Revista Brasileira de Cineantropometria \& Desempenho Humano, 19(1), $128-138$.

Carlock, J. M., Smith, S. L., Hartman, M. J., Morris, R. T., Ciroslan, D. A., Pierce, K. C., ... \& Stone, M. H. (2004). The relationship between vertical jump power estimates and weightlifting ability: a field-test approach. The Journal of Strength \& Conditioning Research, 18(3), 534-539.

Duthie, G. M., Young, W. B., \& Aitken, D. A. (2002). The acute effects of heavy loads on jump squat performance: An evaluation of the complex and contrast methods of power development. The Journal of Strength \& Conditioning Research, $16(4), 530-538$.

Everett, G. (2009). Olympic weightlifting: A complete guide for athletes \& coaches. Sunnyvale: Catalyst Athletics.

Fatouros, I. G., Jamurtas, A. Z., Leontsini, D., Taxildaris, K., Aggelousis, N., Kostopoulos, N., \& Buckenmeyer, P. (2000). Evaluation of plyometric exercise training, weight training, and their combination on vertical jumping performance and leg strength. The Journal of Strength \& Conditioning Research, 14(4), 470-476.

Harman, E. A., Rosenstein, M. T., Frykman, P. N., \& Rosenstein, R. M. (1990). The effects of arms and countermovement on vertical jumping. Med Sci Sports Exerc, 22(6), 825-833.

McGuigan, M. R. (2017). Developing power. Human Kinetics.

Nuzzo, J. L., McBride, J. M., Cormie, P., \& McCaulley, G. O. (2008). Relationship between countermovement jump performance and multijoint isometric and dynamic tests of strength. The Journal of Strength \& Conditioning Research, 22(3), 699-707.

Olympic.org (2019). Weightlifting. Retrieved from: http://www.olympic.org/weightlifting.

Otto, W. H. , Coburn, J. W. , Brown, L. E. \& Spiering, B. A. (2012). Effects of Weightlifting vs. Kettlebell Training on Vertical Jump, Strength, and Body Composition. Journal of Strength and Conditioning Research, 26(5), 1199-1202. doi:10.1519/JSC.0b013e31824f233e.

Robbins, D. W. (2005). Postactivation potentiation and its practical applicability: a brief review. Journal of Strength and Conditioning Research, 19(2), 453.

Takano, B. (2012). Weightlifting programming: A winning coach's guide. Catalyst Athletics.

Tricoli, V., Lamas, L., Carnevale, R., \& Ugrinowitsch, C. (2005). Short-term effects on lower-body functional power development: weightlifting vs. vertical jump training programs. The Journal of Strength \& Conditioning Research, 19(2), 433-437. 